\title{
El ocre que vino del cielo
}

\author{
Víctor M. Díaz Núñez de Arenas \\ Universidad Complutense de Madrid. Cultura de Ribera \\ victordna@movistar.es
}

RESUMEN: Al igual que nuestra sociedad contemporánea busca en determinados comportamientos de los animales caminos para la empatía interespecies, en el origen de nuestro pensamiento simbólico hubo estrategias empáticas hacia los demás seres con los que compartíamos hábitat, conductas que, por apropiación mimética, son el inicio de nuestro pensamiento místico y de las manifestaciones estéticas asociadas a él. Analizando el comportamiento cosmético del quebrantahuesos (Gypaetus barbatus) y el registro fósil neandertal y el del inicio de la colonización de Europa por el sapiens, donde aparecen los primeros instrumentos musicales del continente, presentamos algunas de esas estrategias en el origen de la conciencia simbólica en relación con el sueño arquetípico de vuelo y con la observación de aves.

PALABRAS CLAVE: Cosmética de las aves; Memoria cultural; Ocre; Quebrantahuesos; Simbolismo; Sueño de vuelo.

\section{The Ocher that Came from Heaven}

ABSTRACT: Just as our contemporary society seeks in certain animals' behaviors ways for interspecies empathy, at the origin of our symbolic thought there were empathic strategies towards the other beings with whom we shared habitat, behaviors that, by mimetic appropriation, are the beginning of our mystical thinking and the aesthetic associated with it. Analyzing the cosmetic behavior of the bearded vulture (Gypaetus barbatus) and the neanderthal fossil record and the beginning of the colonization of Europe by sapiens, where the first musical instruments of the continent appear, we present some of these strategies at the origin of the symbolic consciousness in relation to the archetypal dream of flight and with bird watching.

KEYWORDS: Bird Cosmetics; Cultural Memory; Ocher; Bearded Vulture; Symbolism; Dream of Flight.

Recibido: 28 de enero de 2019 / Aceptado: 24 de mayo de 2019.

\section{En otra piel}

La simple pregunta Por qué cantan los pájaros lleva al filósofo y músico estadounidense David Rothenberg a plantear un asunto de mayor profundidad ante el panorama de crisis socioecológica en el inicio de este siglo XXI: «¿cuáles de nuestras habilidades humanas pueden resultar más útiles para introducirse en la mente de otras especies animales?» (Rothenberg, 2006: 11). La cuestión es fundamental: más allá de lo puramente científico, establece un claro camino para algo esencial si queremos revertir la actual sobreexplotación fruto, además del insaciable apetito material de la economía capitalista, de una absoluta falta de empatía hacia el resto de los seres vivos, de los procesos y de las formaciones inertes con las que compartimos la existencia.

Estamos de acuerdo con Rothenberg y con tantos otros que, como él, ven en la empatía la única forma de revertir la actual crisis socioecológica, algo que, a la vista de las voluntades y los resultados, parece complicado en el corto y medio plazo. Sin embargo, ella es uno de los factores fundamentales que nos ayudan a comprender aquello que siempre nos ha fascinado y debe ser tomada como punto de partida para, una vez entendidas las causas ya no de nuestro alejamiento, sino del ataque hacia el resto de la naturaleza, encontrar nuevas maneras de tener una vida coherente con nuestra escala.

El análisis de lo que se consideran comportamientos estéticos y su importancia en la evolución de las especies animales no humanas nos ha llevado a plantear la siguiente reflexión sobre el papel que ha jugado la convivencia con las

Cómo citar este artículo: DÍAZ NúÑEZ DE ARENAS, Víctor M., «El ocre que vino del cielo", Boletín de Arte-UMA, n. ${ }^{\circ} 40$, Departamento de Historia del Arte, Universidad de Málaga, 2019, pp. 115-121, ISSN: 0211-8483, e-ISSN: 2695-415X, DOI: http://dx.doi.org/10.24310/BoLArte.2019.v0i40.5711 
aves en la creación del pensamiento simbólico humano. La estrecha relación con determinadas especies indica, comparando los estudios etológicos con el registro fósil, que los humanos, sapiens y muy probablemente neandertales, mantenían un contacto muy cercano con ciertos grupos de aves que parecen haber sido fundamentales en el inicio tanto del comportamiento místico como del lenguaje estético por el que, en gran medida, el primero se expresa simbólicamente. Vestir sus plumas parece el camino más inmediato, pero hay otros signos que, demostrada esta íntima convivencia sin un aparente fin práctico, nos llevan a pensar en ciertas apropiaciones miméticas, tanto materiales como abstractas, que habrían sido tomadas de las aves en el origen de nuestras manifestaciones estéticas tal como hoy las entendemos.

\section{Sueños de vuelo}

Nuestra experiencia de la naturaleza está mediada por las aves como las otras formas de vida más inmediatamente perceptibles por los sentidos. Esta afirmación es válida tanto en el plano individual como en el plano social: son innumerables las culturas sobre el planeta que las tienen como elemento central de su mitología y de su comportamiento simbólico. Nos intriga su fisionomía y su etología, nos fascinan su canto y el colorido de sus plumas, todos ellos elementos que también conforman nuestra experiencia estética consciente. Pero es su rasgo fundamental el que inconscientemente nos ha maravillado desde tiempo ancestral: el carácter de seres flotantes que les otorga su capacidad de vuelo, estado que los humanos perdemos al nacer y que añoramos durante el resto de nuestras vidas, aquello que nos libera de nuestra condición de horizontalidad sobre el plano de las cosas y nos permite elevarnos sobre ellas, penetrarlas, fluida y dinámicamente, en el leve espacio físico que supone la verticalidad. Estado que, en manos de la técnica, destrozó el siglo XX por aceleración: la materialización técnica de nuestro sueño de poder volar fue el pistoletazo de salida para la actual situación de sobreexplotación de los recursos. Fue la última barrera que nuestra consciencia logró romper para continuar su ilusión de omnipotencia. Alcanzado el cielo, solo queda el consiguiente descenso a los infiernos.
La técnica, una vez más, vencía a la naturaleza y esta vez, nada más y nada menos que a una ley física con validez universal: la gravitación había sido derrotada. Su equivalencia en el nivel del inconsciente suponía materializar, en el mundo consciente, el que ha sido uno de los comportamientos simbólicos más profusamente manifestados por la humanidad, una de las fuentes de las que manan más generosamente las imágenes arquetípicas de las que se nutren los símbolos: la capacidad de vuelo.

Gaston Bachelard aborda en El aire y los sueños (1989) la cuestión de los estados flotantes y voladores que el ser humano percibe en sus sueños como manifestación inconsciente de nuestro deseo de superar las leyes físicas que nos mantienen pegados a la tierra. Su concepción simbólica estudia el dinamismo de las imágenes en el contexto de la creación del imaginario y como rasgo distintivo de la imaginación frente a la percepción o el recuerdo: «percibir e imaginar son tan antitéticos como presencia y ausencia. Imaginar es ausentarse, lanzarse a una vida nueva» (Bachelard, 1989: 12).

Bachelard coloca el aire, medio natural de los pájaros, como el elemento más cercano a libre: «el aire natural es el aire libre» (Bachelard, 1989: 18) y apela a la simpatía material como desencadenante de los mecanismos de una participación verdaderamente dinámica. Buscando en la intimidad de lo real es como lograremos agitar la nuestra, consiguiendo una inversión del sujeto y del objeto. La correspondencia material que establecemos entre las cosas y nosotros es la mejor prueba del dinamismo de los objetos.

Sobre los principios fenoménicos de «alcance, ascensión y sublimación», la invitación al viaje aéreo se realiza en base a un ligero movimiento ascendente, propio de una "psicología ascensional» caracterizada, precisamente, por ellos. Nuestro amor por los pájaros está basado, en parte, en el alivio y la alegría fruto de la sensación de elevación producida por el ascenso. De los cuatro elementos sobre los que Bachelard basa su fenomenología del sueño, el aire ha sido el último que salió de los nuestros. Fuego y agua han sido experiencias dominadas desde antiguo en el campo de lo material, pero dependemos del suelo, vivimos pegados a la tierra.

Explorar la verticalidad que se suponía inalcanzable ha condicionado nuestro porvenir. El término vertical deja, así, de ser una metáfora para convertirse en un orden material, 
matemático, determinante para la evolución psíquica de los seres humanos. Las emociones que nos «alivian» o "entorpecen», evolucionan en una «diferencia vertical», en aquello «que designa mejor su eficacia, su destino psíquico» (Bachelard, 1989: 20), el de algo que no tiene explicación y lo explica todo.

Los sueños de vuelo, experiencia frecuente en los seres humanos, nos permiten vivir en esa ambivalencia de la realidad que se comprende como un sueño y del sueño que se comprende como real durante el breve instante en el que no estamos inmersos en él. Por el vuelo nocturno buscamos una «psicología natural» que analice los sucesos sin apriorismos usando la imaginación dinámica como método para "distinguir entre las imágenes ficticias y las verdaderamente naturales» (Bachelard, 1989: 24-33). Superada la voluptuosidad psicoanalítica con respecto al vuelo onírico, hay una huella más profunda que estos sueños dejan sobre nuestro ser y que nos sitúa en los campos de la ingravidez y la pesantez: «nuestro ser onírico es 'uno'. Continúa de día la experiencia de la noche» (Bachelard, 1989: 34).

\section{Los baños del quebrantahuesos}

El vuelo es la característica física más evidente de las aves. Pero tienen otras tan efectivas sobre nuestra percepción como el nexo con el inconsciente que supone contemplar el acto del vuelo durante la vigilia. La primera es su color que, sin duda, formó parte de esa experiencia en el origen de nuestra consciencia estética. Es ingenuo pensar que hubo algún momento donde, respeto interespecies mediante, las aves dejasen que los humanos las observásemos con calma y que de ahí parta la fascinación por el color y su manejo incesante a lo largo de nuestra evolución como especie. Menos lo es que no siempre tuvieron sus hábitat tan reducidos como en nuestros días y que, por tanto, su número sería mucho mayor, haciendo más probable su observación y añadiendo, además, ese factor huidizo que debe tener todo lo que está entre lo mágico y lo bello. Esa experiencia visual no se presentaba aislada e inerte en lo sensorial, como en el caso de las plantas o de los minerales con brillantes colores. Está asociada al canto y a la dinámica flotante del vuelo, de manera que tampoco resulta complicado imaginar desde qué pronto está en nuestra consciencia estética la tan frecuente asociación sinestésica entre sonido y color. Todas estas cualidades se concentraban en unos seres dotados de una vida muy similar a la nuestra, con los que compartíamos los mismos bosques, las mismas estepas, las mismas cuevas en cuyas paredes luego dejaríamos las primeras huellas estables de nuestra consciencia estética.

En esos primeros momentos de la consciencia humana, las aves carroñeras y las grandes rapaces eran competidoras por los restos de carne y enemigas potenciales: no es difícil imaginarlas elevando a un homínido inmaduro en sus garras tal como hacen con otras especies de peso similar al de una de nuestras crías, siendo, desde entonces, ser supremo entre aquellos que vuelan y, por tanto, temor celeste de los humanos.

Pero al menos a la vez, si no antes, debieron ser ejemplo para nuestra alimentación. Pensemos en el proceder del quebrantahuesos (Gypaetus barbatus), que toma los huesos de los grandes herbívoros en sus garras, se eleva con ellos y los lanza contra determinadas rocas para romperlos y comer la médula de su interior. No se conocen muchos comportamientos como este en otros animales, pero sí existe cierto consenso en la importancia que para nuestra evolución tiene el acto de golpear huesos contra las piedras para sacar la médula.

El poder reproductivo de determinados objetos simbólicos o rituales sirve como base de las estructuras conectivas donde se generan los modelos reconocibles que facilitan la identificación, uniendo determinadas expresiones de la memoria que van generando su construcción social. Observemos algo más cercano que este comportamiento alimentario, algo que salta a la vista. Hay conductas de las aves que pueden calificarse como estéticas y algunas de ellas están asociadas a la fijación por un color que, incluso, al no poseer en su cuerpo, obtienen del exterior de diversas materias y formas. Este es el caso del quebrantahuesos, que toma su característico color herrumbroso de fuentes de agua ferruginosa (Negro et al, 1999).

El peculiar color rojizo de las plumas ventrales y de la garganta que vemos cuando se observa a una de estas actualmente escasas aves en libertad llamó la atención de los investigadores, que veían cómo los ejemplares nacidos en cautividad mantenían el color blanco al adquirir el plumaje de adulto, algo que no sucedía en el de las aves en libertad. Identificado el pigmento como óxido de hierro a finales 
del siglo diecinueve, las hipótesis de la adquisición del color indicaban que esta se producía de manera indirecta: para unos, por una alimentación rica en carotenoides que, como supuestamente sucede también en otras especies, les aportaría el tono a medida que las aves iban teniendo más edad; para otros, al rozar las aves sus plumajes con posaderos ricos en este mineral.

Finalmente, pudo comprobarse lo equivocado de ambas suposiciones. Bastó con ofrecer a las aves la posibilidad de obtener el color impregnando el suelo húmedo de sus jaulas para que, sin vacilar, lo repartieran entre sus plumas. El comportamiento no era casual, actuaban de manera diferente si se les presentaba disuelto y extendido, que si se les ofrecía la posibilidad de tomar un baño en agua ferruginosa: en el elemento líquido, se sumergían y sacudían el sobrante agitando sus plumas; ante el suelo humedecido, primero, se frotaban contra él para, una vez tomado, extender metódicamente el color, primero desde la zona ventral hacia los hombros y la espalda y luego, hacia abajo, siguiendo por las patas, hasta las garras. Finalmente, balanceando la cabeza entre los hombros y la espalda, toman el color en ella. Este ritual dura, aproximadamente, una hora y se da con mayor intensidad en los individuos adultos y en las hembras, aunque también los jóvenes lo practican a pesar de lo escaso del recurso, de modo que no es parte del cortejo. Tomado, de entrada, con toda cautela, a final del pasado siglo, pudo comprobarse este mismo comportamiento cosmético en ejemplares en libertad de los Pirineos y los Alpes. En esas observaciones pudieron corroborar otra pauta no menos llamativa asociada a la de la adquisición del color: tanto en libertad como en cautividad, las aves son muy reservadas cuando toman estos baños y su recelo, si algo las molesta en el proceso, supone su interrupción y su inmediato abandono.

Las fuentes de agua ferruginosa son, por tanto, tan importantes para la conservación del quebrantahuesos como disponer de huesos de grandes herbívoros con los que alimentarse. Este comportamiento de atracción del animal hacia el rojo no para en la decoración de su plumaje: la madera y las hojas rojizas producen el mismo efecto fascinante que los suelos impregnados de óxido de hierro. Las investigaciones establecen que el tono rojizo, presente también en el anillo escleral y en el iris, proporciona información sobre el estatus del ave. Su presencia solo en esas dos partes del cuerpo es causada por una dieta pobre en carotenoides, de manera que, tiñendo sus plumas, habrían encontrado una forma creativa de mostrar más claramente esa señal de estatus que su alimentación no les proporciona.

Años después y ante las respuestas pragmáticas que apuntaban, por ejemplo, a que el barro pudiera actuar como antiséptico, tal como lo usan los mamíferos que se revuelcan en esos lodos, o que sirvieran para estimular la producción de vitamina A en los embriones, mediante un complejo sistema que supone atravesar la cáscara del huevo para que el no nato lo absorba en su bolsa embrionaria, las mismas personas que realizaron el descubrimiento replantearon su teoría sin abandonar la conclusión inicial de la adquisición intencionada del color (Negro et al, 2002). Sin desechar del todo lo que en principio parece algo descabellado, la cuestión es que las aves se ocupan de crear un estímulo visual para las otras mediante un comportamiento realizado al efecto y sea o no asunto de estatus o de higiene, el caso es que esa conducta está asociada con la selección sexual, como se comprueba por las diferencias de intensidad en la pigmentación que los investigadores han encontrado en individuos que comparten territorio en libertad.

La observación de las aves es algo que maravilla a los seres humanos. Los modernos aparatos ópticos nos permiten hacerlo desde la distancia aséptica que nos otorga la ciencia, pero esta distancia no siempre ha sido tal: al compartir los mismos hábitat, las primeras observaciones de esta conducta debieron producirse en un ámbito más íntimo, estimulante de otras sensaciones, entre ellas, las de la apropiación mimética de determinados comportamientos, como los baños con pigmentos, que contribuyeran a lograr, mediante una conducta consciente y adquirida, otro de los atributos que posee quien realiza el comportamiento a imitar, en este caso, volar durante la vigilia como se hace soñando.

\section{El simbolismo ancestral de los buitres}

Pintar el cuerpo con ocre es una de las primeras manifestaciones del comportamiento simbólico en los homínidos. Existe menos acuerdo sobre si es un asunto exclusivo de la especie sapiens, si también lo fue de la neandertal, o si ya era una cualidad consciente del antepasado común que tenemos. Partiendo de esta premisa, el ocre ya aparece en 
contextos arqueológicos datados en fechas neandertales, entre otros lugares, en la Península Ibérica, donde, hasta el momento, se ha encontrado el rastro más antiguo de esta preparación en la Cueva de los Aviones (Cartagena, Murcia), datado, por series de uranio, en unos ciento veinte mil años de antigüedad (Hoffmann et al., 2018a; Hoffmann et al., 2018b), de manera que el comportamiento simbólico no serviría como hecho diferencial entre nosotros y ellos, tal como es del gusto de la actual cultura hegemónica (Hopkison, 2013). El hallazgo de esas conchas con preparaciones de ocre se ha realizado en un contexto marino, cercano al agua, medio flotante por excelencia junto al aire.

Junto con las conchas, los collares de cuentas y la decoración con ocre, garras, huesos y plumas de rapaces parecen completar el registro de la decoración simbólica de los neandertales, de manera que, en una primera y rápida asociación, podría vincularse el incipiente simbolismo de los homínidos con el deseo de flotar, libres del suelo, tanto en el aire como en el agua. Córvidos, rapaces y carroñeros han sido encontrados con profusión en numerosos yacimientos neandertales (Finlayson et al., 2012; Finlayson y Finlayson, 2016; Street y Turner, 2016). Aunque pudiera pensarse, primero, que esa profusión es fruto de la recolección de cadáveres de estas especies, y segundo, que se haya hecho con fines culinarios, lo cierto es que ninguna de las tres familias ha tenido interés para la alimentación humana y que los restos no presentan marcas de haber sido consumidos con ese fin, de manera que es muy razonable pensar que esa profusión se deba a su cría en cautividad con el fin de usar determinadas partes de sus esqueletos y plumajes con un fin simbólico.

De ser ciertas las pruebas, estaríamos no solo ante un comportamiento simbólico por simpatía, sino que habría una verdadera intencionalidad en su realización, un verdadero sistema que se iniciaría con la cría de determinadas especies para la obtención de los atributos simbólicos, lo que, necesariamente significa un uso sistemático de esos elementos en un contexto ritual completamente definido, tanto en sus significantes como en sus significados, con una finalidad muy concreta: hacer conscientemente visibles las cualidades del ser que se portaba en un doble nivel. Primero, como toma de consciencia individual, a través de los elementos físicos del ser volador, me identifico como el soñador de vuelo que soy en la inconsciencia que vivo con la misma intensidad que la consciencia de la vigilia; segundo y al unísono, con respecto al otro, que tal vez tenga los mismos sueños flotantes, pero que no ha dado el paso para mostrarlos conscientemente, puede o no ser un hecho diferencial. En el caso de que el otro sea soñador de vuelo como el portador de esos atributos, un mundo consciente que nace de la inconsciencia se abre, libre como el aire que quieren poblar, ante ellos.

El registro fósil nos ofrece otro elemento datado en un contexto cronológico próximo al inicio de la presencia del sapiens en el occidente europeo que apunta en la misma dirección. Son las flautas realizadas a partir de huesos de ave (Turk, en Mithen 2007: 357; 491-492; Morley, 2006; Conrad, Malina y Münzel, 2009; Diedrich, 2015). Lógico, es más sencillo obtener una flauta del hueso hueco de un pájaro que tallar el interior del duro marfil de un mamífero. Y más lógico todavía en un contexto simbólico donde nos pintamos el cuerpo como el quebrantahuesos y nos adornamos con garras y plumas. El siguiente elemento de las aves que es necesario poseer es su sonido, estímulo sensorial inevitable: uno puede ver o no a un pájaro, pero, en su presencia, es imposible no escucharlos. Y la escucha atenta de ese verdadero silencio de la naturaleza nos abrió las puertas a unos ritmos y unas armonías que no tardaríamos en reproducir.

De hecho, la frontera simbólica que supone la elaboración de instrumentos musicales complejos también se ha tomado como una de esas absurdas barreras para distinguir quienes tienen de quien no. Antes estaba la práctica del ritmo de la naturaleza originaria, golpear con un percutor una piedra, una madera o una piel tensa como acceso a la cadencia. La incorporación de la armonía y la melodía propias de otro tipo de música, para la que es necesario la construcción de instrumentos que suplan nuestra carencia natural para la expresión de una habilidad que no nos ha sido dada por nuestras facultades físicas, sitúa a la expresión musical, por adición, en otro nivel. Es una habilidad destinada desde su origen a la estimulación del campo simbólico y, por tanto, que se desarrolla en el campo de lo sensible. Pero no del de lo sensible natural, sino, ya, dentro del de lo sensible artificial, o, al menos, de lo sensible estimulado por el artificio. Creando un ritmo artificial, el ser humano se pone por primera vez frente a la naturaleza y no dentro de ella (Schneider, 2010).

Especialmente reseñable es el hallazgo en el año 2009, en los yacimientos de Hohle Fels y Vogelher (Conrad, 
Malina y Münzel, 2009), de restos fragmentarios de tres flautas hechas con marfil y una casi completa realizada sobre el radio de un ave de gran tamaño, un buitre leonado (Gyps fulvus). Fue denominada como Flauta I de Hohle Fels y datada con una antigüedad superior a los treinta y cinco mil años, siendo el contexto estratigráfico en el que se encontró de unos cuarenta mil, momento de la llegada a Europa del ser humano moderno.

De nuevo la presencia de un carroñero en el origen de un comportamiento simbólico de los homínidos, una prueba más de la importancia que la observación de las aves ha tenido para ese campo. Se posee el vuelo con las plumas, el poder con las garras, el esqueleto necesario para elevarse con los huesos huecos, el color con el ocre y solo queda por adquirir, además de la reproducción de la imagen, lo que el ave posee en su interior. La aparición de estos objetos en esa fecha en torno a los cuarenta mil años de antigüedad añade un interesante elemento para la comprensión de la generación del lenguaje en nuestra especie, así como apuntan a que ya el neandertal, además de un comportamiento simbólico definido o precisamente como fruto de tenerlo, poseía cierto lenguaje articulado. El canto, lo que sale del interior del ave, debía estar, pues, dentro de ellas y los huesos de los grandes carroñeros tienen lo necesario para realizar los instrumentos precisos que extraigan la melodía de ese interior. Soplar dentro de esos huesos, además, suma el sonido del cielo a la música que surgía al golpear la tierra o las pieles de los animales que la simbolizan. No podemos olvidar que el sonido del cielo no proviene solo del interior de las aves, también el deslizar de las plumas cerca de nosotros produce un característico silbido, el ritmo del vuelo, fácilmente reproducible con un instrumento por el que se pueda introducir y modular el aire.

Martin Poor (2010) examina el arte mobiliario del auriñacense del sudeste alemán, entre otros, los yacimientos estudiados por Conrad, Malina y Münzel (2009), desde la perspectiva del concepto de memoria cultural propuesto por Jan Assmann (2011). Dibujando un itinerario del marco cognitivo sobre el que se asentaría la memoria cultural del Paleolítico Superior, parte de la base de unas sociedades con una conciencia dinámica, que confeccionan un saber y una autoimagen comunes como nexo colectivo apoyado tanto en reglas y valores, como en el recuerdo de un pasado conjunto. Para Assmann (2011: 18-23), la memoria cultural es, junto con la memoria mimética, la memoria de las cosas y la memoria comunicativa, "una de las cuatro dimensiones exteriores de la memoria».

Su análisis no se centra en la citada flauta, sino en diferentes figuras talladas en hueso y marfil que representan animales perfectamente reconocibles. De todas ellas, solo una tiene forma de «ave acuática» y procede, precisamente, del yacimiento de Hohle Fels. Su propuesta se basa en dos elementos: «primero, las esculturas deben ser analizadas en relación con sus características estilísticas y materiales. Segundo, estas observaciones deben realizarse teniendo en cuenta las características ecológicas y etológicas de las especies representadas, incluidos los seres humanos» (Poor, 2010: 97). Así, tendríamos, que, justamente en el lugar donde aparece un instrumento elaborado conscientemente para poseer el sonido del pájaro, se encuentra, excepcionalmente, la figura tallada en hueso de un "ave marina», aves de las que se reproduce, también conscientemente y en el mismo contexto espaciotemporal, incluso con la cría de determinadas especies para ese fin, el contraste cromático entre el blanco y negro de sus plumajes (Street y Turner, 2016), atributo visual de su carácter flotante tanto en el aire como en el agua.

Es demasiado contemporáneo que los símbolos, que la propia comunicación, se desarrollen para separar, resulta más sensato pensar que se fue construyendo para tener referencias comunes con los otros. Observar una posible conexión simbólica entre sapiens y neandertales obliga, como ya se ha dicho, a pensar que ya existía un comportamiento simbólico en un ancestro común que, como otros elementos de su fisiología, evolucionaría en ambas especies demostradas ya como sociales. Esto, evidentemente, es muy complicado que pueda comprobarse en el registro material que nos proporciona la arqueología, solo puede rastrearse en la huella simbólica que ha sobrevivido a la aceleración materialista y a la homogeneización cultural de los últimos siglos. $Y$ ese rastro indica que uno de los ancestros comunes de la comunicación humana en el campo simbólico viene de la convivencia con las aves. 


\section{Bibliografía}

ASSMANN, Jan (2011), Historia y mito en el mundo antiguo. Los orígenes de la cultura en Egipto, Israel y Grecia, Gredos, Madrid.

BACHELARD, Gaston, (1989), El aire y los sueños, FCE, México D. F.

CONRAD, Nicholas J., MALINA, Maria y MÜNZEL, Susanne C. (2009), «New flutes document the earliest musical tradition in Southwestern Germany», Nature, n. ${ }^{\circ}$ 460, pp. 737-740. En: https://www.nature.com/articles/nature08169 (fecha de consulta: 26-02-2019).

DIEDRICH, Cajus G. (2015), «'Neanderthal bone flutes': simply products of Ice Age spotted hyena scavenging activities on cave bear cubs in European cave bear dens", Royal Society Open Science, 2. En: <https://royalsocietypublishing.org/doi/pdf/10.1098/rsos.140022> (fecha de consulta: 26-02-2019).

FINLAYSON, Clive, BROWN, Kimberly, BLASCO, Ruth, ROSELL, Jordi, NEGRO, Juan José, BORTOLOTTI, Gary R., FINLAYSON, Geraldine., SÁNCHEZ MARCO, Antonio, GILES PACHECO, Francisco, RODRÍGUEZ VIDAL, Joaquín, CARRIÓN, José S., FA, Darren A. y RODRÍGUEZ, José M. (2012), «Birds of a Feather: Neanderthal Exploitation of Raptors and Corvids», PLoS ONE, 7, 9. En: <https:// journals.plos.org/plosone/article?id=10.1371/journal.pone.0045927> (fecha de consulta: 26-02-2019).

FINLAYSON Stewart y FINLAYSON Clive (2016), «The birdmen of the Pleistocene: On the relationship between Neanderthals and scavenging birds», Quaternary International, 421, pp. 78-84. En: <https://www.sciencedirect.com/science/article/pii/S1040618215014512> (fecha de consulta: 26-02-2019).

HOFFMANN, Dirk L., ANGELUCCI, Diego E., VILLAVERDE, Valentín, ZAPATA, Josefina y ZILHÃO, João (2018a). «Symbolic use of marine shells and mineral pigments by Iberian Neandertals 115,000 years ago", Science Advances, 4, 2. En: http://advances.sciencemag. org/content/4/2/eaar5255 (fecha de consulta: 26-02-2019).

HOFFMANN, Dirk L., STANDISH, Christopher D., GARCÍA-DÍEZ, Marcos, PETTITT, Paul B., MILTON, James A., ZILHÃO, João, ALCOLEA-GONZÁlEZ, José J., CANTALEJO-DUARTE, Pedro, COLLADO, Hipólito, DE BALBíN, Rodrigo, LORBLANCHET, Michel, RAMOS-MUÑOZ, José, WENIGER, Gerd-Christian y PIKE Alistair W. G. (2018b) «U-Th dating of carbonate crusts reveals Neandertal origin of Iberian cave art», Science, n. ${ }^{\circ}$ 359, 6378, pp. 912-915. En: <http://science.sciencemag.org/content/359/6378/912> (fecha de consulta: 26-02-2019).

HOPKINSON, Terry (2013), “'Man the symboller”. A contemporary origins myth», Archaeological Dialogues, 20, 2, pp. 215-241. En: <https://www.cambridge.org/core/journals/archaeological-dialogues/article/man-the-symboller-a-contemporary-origins-myth/804F8D5CC1ADE500CFC1115059139057> (fecha de consulta: 26-02-2019).

MITHEN, Steven (2005), Los neandertales cantaban rap. Los orígenes de la música y el lenguaje, Crítica, Barcelona.

MORLEY, Iain (2006), «Mousterian musicianship? The case of the Divje Babe I bone», Oxford Journal of Archaeology, 25, 4, pp. 317-333. En: <https://onlinelibrary.wiley.com/doi/abs/10.1111/j.1468-0092.2006.00264.x> (fecha de consulta: 26-02-2019).

NEGRO, Juan José, MARGALIDA, Antoni, HIRALDO, Fernando y HEREDIA, Rafael (1999), "The function of the cosmetic coloration of bearded vultures: when art imitates life», Animal Behaviour, n. ${ }^{\circ}$ 58, pp. F14-F17. En: <https://www.sciencedirect.com/science/article/ pii/S0003347299912514> (fecha de consulta: 26-02-2019).

- (2002), «Iron oxides in the plumage of bearded vultures. Medicine or cosmetics?», Animal Behaviour, n. ${ }^{\circ}$ 64, pp. F5-F7. En: https://pdfs. semanticscholar.org/af65/cc9e29519dd65a73c90adf70595e751b09e6.pdf (fecha de consulta: 26-02-2019).

POOR, Martin (2009), «Palaeolithic Art as Cultural Memory: A Case Study of the Aurignacian Art of Southwest Germany», Cambridge Archaeological Journal, 20, 1, pp. 87-108. En: <https://www.cambridge.org/core/services/aop-cambridge-core/content/view/7CDE9AD4A3D03C55FE0A379B44AE858D/S0959774310000065a.pdf/palaeolithic_art_as_cultural_memory_a_case_study_of_the_ aurignacian_art_of_southwest_germany.pdf> (fecha de consulta: 26-02-2019).

ROTHENBERG, David (2006), Por qué cantan los pájaros, Barrabés, Benasque.

SCHNEIDER, Marius (2010), El origen musical de los animales-símbolos en la mitología y la escultura antiguas, Siruela, Madrid.

STREET, Martin y TURNER, Elaine (2016), «Eating crow or a feather in oness cap: The avifauna from the Magdalenian sites of Gönnersdorf and Andernach-Martinsberg (Germany)», Quaternary International, 421, pp. 201-218. En: https://www.sciencedirect.com/science/article/pii/S1040618215009659?via\%3Dihub (fecha de consulta: 26-02-2019). 